\title{
RECUPERACIÓN TIPOLÓGICA DE CUATRO IGLESIAS RURALES (MADRID, ESPAÑA)
}

\author{
(TYPOLOGICAL RESTORATION OF FOUR RURAL CHURCHES. \\ MADRID, SPAIN)
}

Javier Gutiérrez Marcos, arquitecto

Jefe del Servicio de Conservación y Restauración del

Fecha de recepción: 4 - VIII - 93

Patrimonio Histórico Inmueble de la Comunidad de Madrid

\section{RESUMEN}

La restauración de cuatro iglesias rurales de la Comunidad de Madrid con problemática común: la pérdida tipológica y estructural, la cubierta con la madera como material primordial y la recuperación del esquema arquitectónico para permitir su lectura histórica.

En la de Camarma se recuperan y muestran sus elementos mudéjares: ábside, anteábside, techumbre y pinturas murales, además de resolverse problemas estructurales en fábricas próximas a la ruina.

En Torremocha se desenmascara la estructura oculta y se muestra escalonadamente su evolución arquitectónica con un esquema fácilmente comprensible.

Braojos representa la eliminación de actuaciones inapropiadas mediante la recuperación del esquema constructivo con un lenguaje y unos materiales tradicionales.

Por el contrario, en Chapinería, y partiendo de una situación asimilable a la de Braojos, se plantea la recuperación espacial mediante soluciones arquitectónicas, constructivas $y$ formales muy actuales.

\section{SUMMARY}

The article describes the restoration of four rural churches in the Madrid Community with a common set of problems: the typological and structural loss, mainly wooden roof, and the retrieval of the architectural scheme in order to enable its comprehension in the historical context.

In the church of Camarma, Mudejar elements: apse, anteapse, roofing and mural paintings are restored and displayed. Also, the structural problems in walls that were close to collapsing are solved.

En Torremocha, the concealed structure is being revealed and its architectural evolution is shown step by step with an easily comprehensible scheme.

The Braojos case represents the elimination of inapropriate actions through the retrieval of the construction scheme of a traditional language and with traditional materials.

On the contrary, in Chapineria, a case similar to that of the Braojos one, what is required is the the spatial restoration through very current architectural, constructive and formal solutions.
Presentamos cuatro actuaciones llevadas a cabo por el Servicio de Conservación y Restauración del Patrimonio Histórico de la Comunidad de Madrid, cuatro actuaciones con un denominador común, se trata de obras de restauración en cuatro pequeñas iglesias rurales que han sufrido a lo largo de su his- toria intervenciones que deterioraron su esquema tipológico y estructural y, en algunos casos, con aparición de un proceso de ruina en diferentes grados. Obras encaminadas fundamentalmente a la recuperación del espacio arquitectónico. Obras en las que la estructura de cubierta es un elemento 
esencial, el hilo conductor de las intervenciones, en las que se pasa de la restauración más pura de los elementos originales -en la Iglesia de Camarma- a la liberación de dichos elementos, del enmascaramiento a que habían sido sometidos - como es el caso de Torremocha-, a la recomposición virtual del elemento estructural conformador, ya sea con un lenguaje tradicional -como en Braojos- ya sea con un lenguaje actual tanto constructivo como figurativo -como sucede en Chapinería-, aportando soluciones muy variadas y todas ellas válidas para resolver problemas, en algunos casos, conceptualmente similares.

Se trata de iglesias que nos han llegado tras una costosa y variada adaptación a las necesidades de la población a la que han dado servicio. El paso del tiempo y de la historia se plasma en su arquitectura, es el resultado de un crecimiento casi orgánico a lo largo de los siglos con intervenciones arquitectónicas de dispar fortuna. El templo crece con las necesidades espaciales de cada momento sin derribar sus estructuras anteriores, que se van superponiendo y complementando.

Las intervenciones tratan fundamentalmente de resolver problemas constructivos, pero también de ordenar el esquema estructural para permitir una lectura tipológica del edificio, de las diferentes épocas de su construcción y de las técnicas constructivas empleadas, eliminando elementos extraños que dificultan su comprensión, es decir estamos hablando de Restauración arquitectónica en el más amplio sentido de la palabra; donde la investigación arqueológica es un instrumento fundamental para el conocimiento del edificio y la toma de decisiones proyectales.

Un último nexo de unión en estas intervenciones es el empleo de la madera como elemento esencial en la configuración estructural de las cubiertas. La madera, empleada tanto a la manera tradicional como con la tecnología más actual.

\section{Iglesia de San Pedro, en Camarma de Esteruelas}

Camarma de Esteruelas es un municipio con 1.400 habitantes situado en el área de influencia de Alcalá de Henares, a $36 \mathrm{~km}$ de Madrid.

\section{Reseña bistórica y tipológica}

La Iglesia de San Pedro es un ejemplo de iglesia rural que se corresponde casi canónicamente con las que se han definido con anterioridad.

Su construcción inicial data probablemente del momento histórico, siglo XII, en que tras el avance cristiano en la meseta sur, se ordena que cada lugar de la diócesis de Toledo construya su propia iglesia.
De esta fecha datarán el ábside románico-mudéjar, de tres cuerpos de arquillos de medio punto en ladrillo y cubierto con bóveda de horno, y el anteábside, tras el arco formero, cubierto en su día por bóveda de medio cañón, hoy desaparecida. A continuación se desarrolla un templo de tres naves edificado entre 1560 y 1568 , por el maestro cantero Martín de Múgica; sus fachadas son de mampostería y ladrillo, y en su interior, las tres naves se configuran mediante columnas platerescas que soportan arcos de medio punto. La nave central se cubre mediante alfarje con tirantes dobles, mientras que las laterales lo hacen con techumbres a un agua. A los pies del templo se abre una portada con arco de

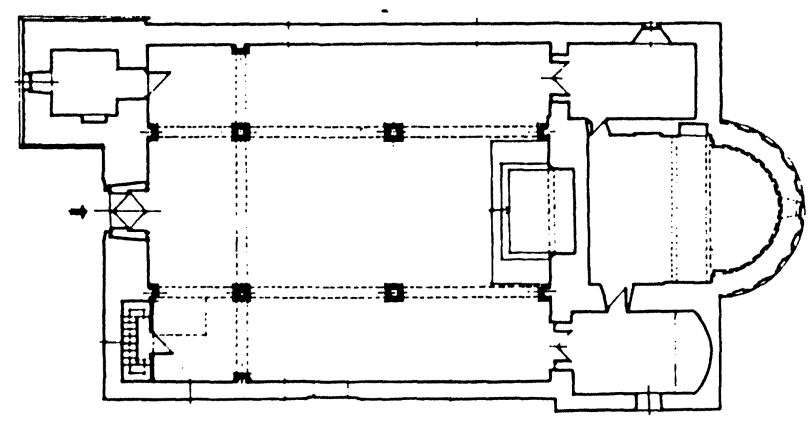

San Pedro. Camarma. Planta anterior a la eliminacion de las capillas del anteábside.

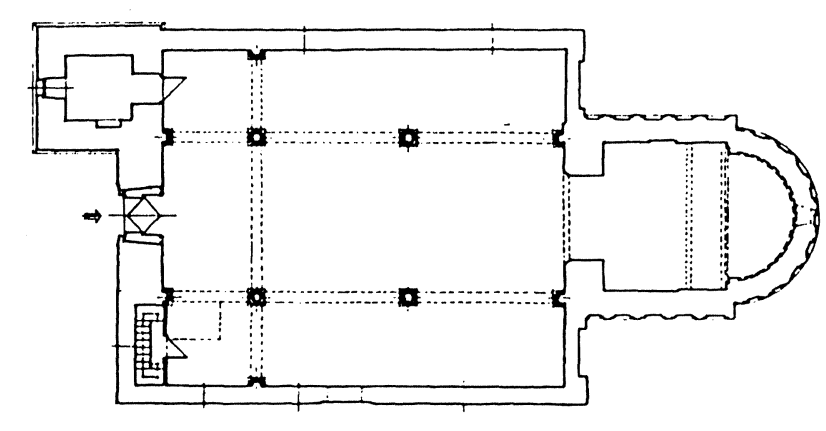

San Pedro. Camarma. Planta actual. 


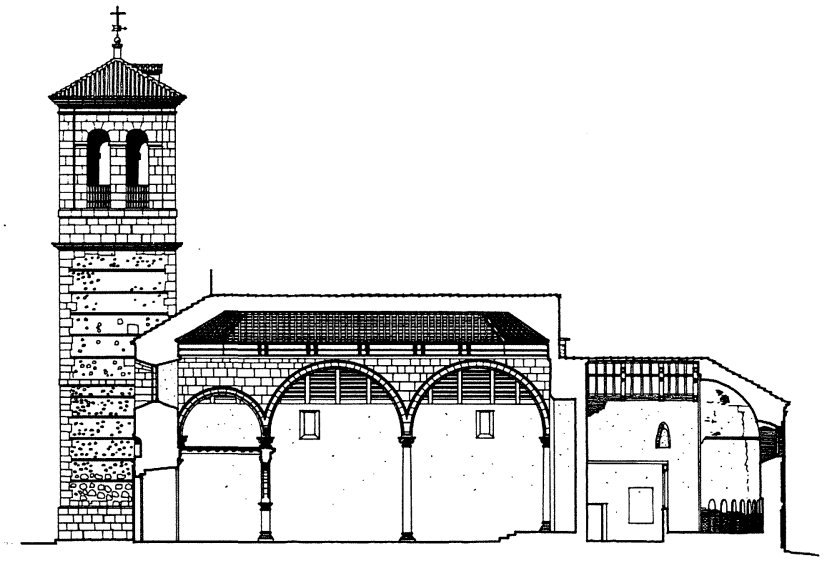

Sección longitudinal anterior a la restauración.

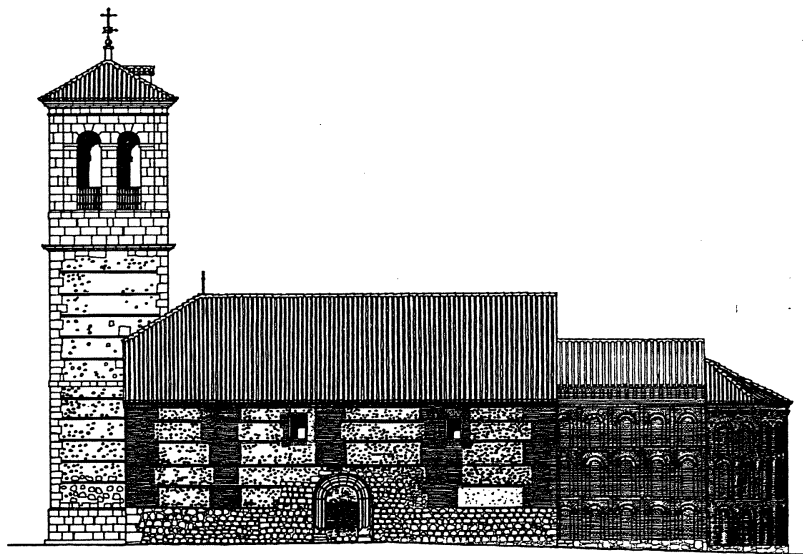

Alzado de mediodía después de la restauración. medio punto con hornacina plateresca y herrajes del siglo XVII, época en la que también se edifica el cuerpo superior de la torre. Con posterioridad se cierra la cabecera y se añaden sendos cuerpos sobre el anteábside, para sacristía y otras dependencias, ocultándose su arquería mudéjar. El interior del ábside y anteábside presenta pinturas murales fechables en los siglos XIV y XV.

La Iglesia es Monumento Histórico-artístico (incoado en 1982).

\section{La restauración}

El proceso de recuperación se ha llevado a cabo en tres fases claramente diferenciadas y ordenadas, según las prioridades que ha impuesto el propio edificio de acuerdo con sus necesidades estructurales y constructivas y las disponibilidades económicas.

En 1982, cuando se inicia el expediente de declaración monumental, el ábside presenta al exterior grandes grietas y desplomes y se encuentra en estado próximo a la ruina. En su interior y bajo superficies ennegrecidas se adivinan posibles pinturas murales. El anteábside ya había perdido su bóveda de medio cañón. La semicúpula del ábside estaba desmembrada a gajos, lo que propiciaba la entrada de agua y como consecuencia la ruina de los muros de sostén, a los que sólo ayudaban los cuerpos adosados que hacían de contrafuertes, de los que, por otro lado, se intuía la necesidad de su eliminación para poner en valor el ábside completo. Todo ello puso en evidencia la falta de cimentación de los paramentos mudéjares.

El proceso comienza con la investigación del alcance de las lesiones estructurales y el muestreo de los paramentos para establecer la extensión de las pinturas murales y el programa de trabajo.

En primer lugar se diseñó un potente apeo metálico que habría de colocarse por el exterior, para permitir la fijación y consolidación de las pinturas, evitando cualquier riesgo de desplome. Antes de cualquier otro trabajo se acometió el recalce por puntos, de forma que tras colocar gran número de testigos seriados y apuntalar provisionalmente con maderas algunas zonas muy disgregadas, se procedió a la ejecución de los dados de cimentación por puntos alternados. Paralelamente y a nivel de cornisa se establecía un zuncho perimetral, así se logró la estabilización de los movimientos de desplome detectados por la rotura de los testigos. Aprovechando la excavación de maniobra realizada para la realización de la cimentación se construyó una pantalla drenante y de ventilación y se conectó a la red de saneamiento. El apeo definitivo se instaló apoyado sobre grandes zapatas de hormigón. Eliminados los riesgos de desplome se acometió la consolidación de las pinturas murales.

Una vez finalizada esta etapa, y protegidos los paramentos interiores contra la intemperie, se procedió al desmontaje de las cubiertas y estructura del ábside, construyéndose un nuevo arco fajón de hormigón trasdosado al de ladrillo existente y a un zuncho de coronación semicircular. Posteriormente se procedió a reforzar el casquete del ábside tras el acuñamiento y sellado de grietas, previo a fijar mediante redondos introducidos con resina, una armadura que pudiera trabajar de forma autónoma y de la que pudiera quedar colgado el casquete primitivo; dicha armadura se hizo solidaria al arco fajón. Esta solución se realizó con carácter excepcional ya que excepcionales eran los daños de la bóveda del ábside, próxima al colapso. 


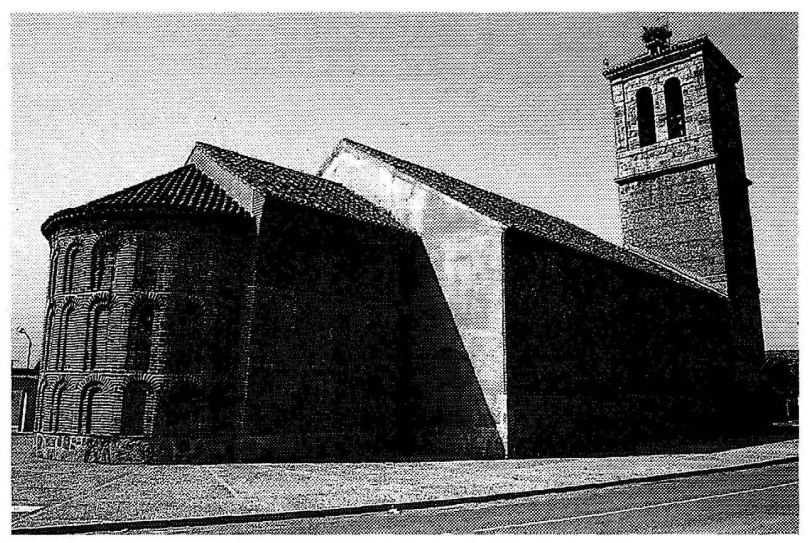

Conjunto después de la restauración.

Una vez afirmadas las estructuras del ábside y de remate de los muros laterales del anteábside se tendió una bóveda de ladrillo en la posición en que estuvo la primitiva y con su espesor, ya que el edificio contaba con los datos suficientes para facilitar su reconstrucción.

A continuación se demolieron los cuerpos adosados al anteábside dejándose la primitiva iglesia a la vista, y se procedió a la recuperación de la filigrana mudéjar de sus muros, restaurándose los paramentos, tratándose las grietas con bordes en distinto plano con cosidos interiores y quedando al exterior simplemente selladas con mortero; también se rehicieron canecillos y cornisas.

Otro aspecto que debe destacarse en esta primera fase fue la documentación, mediante la correspondiente peritación arqueológica, de la posición del muro de cerramiento del lateral de la iglesia originaria.

La segunda fase acometió la restauración de la armadura de la cubierta, en progresivo deterioro, pese a su aparente buen estado. La techumbre cubre las tres naves del templo principal, la central de unos siete metros y medio de luz con armadura de par y nudillo ochavada en sus extremos, y cuyo estribo se equilibró con cinco pares de tirantes que apoyan en ricas ménsulas de talla renacentista. Los extremos de su almizate se trabajan con técnica de lazo, situando en los mismos medias estrellas de dieciséis puntas que recogen los pares de los faldones de la ochava y de los extremos de las gualderas. Las naves laterales se cubren con armaduras de colgadizo.

Se acomete, pues, en esta fase la restauración de las cubiertas, los techos de lacería de la nave principal,

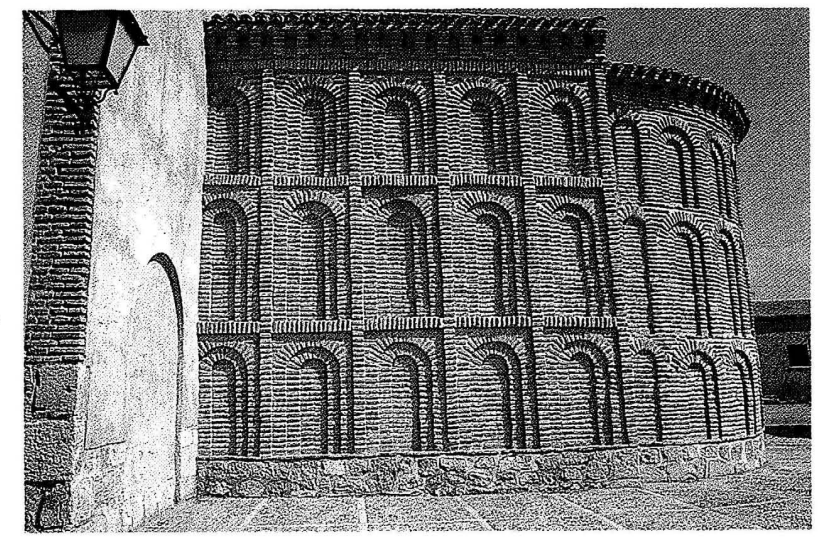

Anteábside después de la restauración.

la alfarjía del coro y naves laterales y la investigación de nuevas pinturas murales. Como obras de menor entidad se eliminan humedades por electroósmosis y se realiza la instalación eléctrica.

En la restauración de los techos destacamos la exhaustiva información que de ellos se obtuvo, procesándose todos los datos mediante ordenador, de forma que las piezas que había que sustituir, y en concreto una pechina del ochavo y la tabla menada, se diseñaron y fabricaron en CAD-CAM, mientras que el resto de los trabajos se efectuó manualmente in situ por los carpinteros de armar: corrección del posicionado de los alfarjes, resinados, el encolado de testas, el encastre de cuadrales..., finalizando el proceso mediante tratamiento antixilófago por impregnación e inyección. Una vez repuesta la tabla menada y los saetinos, y colocado el entablado soporte de la cobertura, se hizo el retejado general con teja vieja.

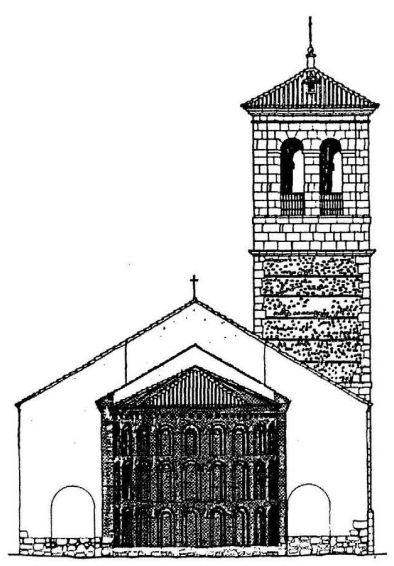

Alzado de levante después de la restauración. 
La tercera fase, realizada en colaboración con el Obispado, que acometió obras interiores de instalación de electricidad, calefacción y solado, consistió fundamentalmente en la restauración del conjunto de pinturas murales, mediante eliminación de revocos y demás elementos que las cubrían, fijación y consolidación de la película pictórica, consolidación de las oquedades del soporte, relleno de lenguas, grietas y picotazos, y reintegración de las pérdidas pictóricas con acuarela mediante la técnica de "regatino".

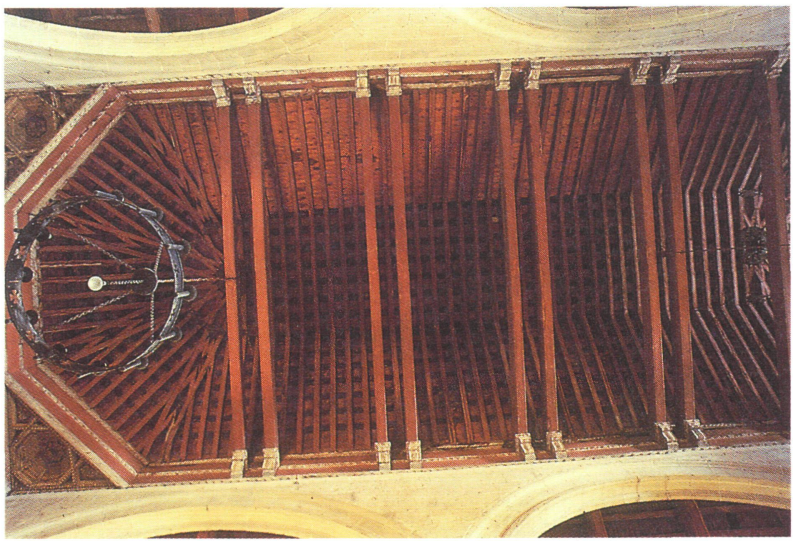

San Pedro. Camarma. Techo de lacería restaurado.

Ficha técnica

\begin{tabular}{|ll|}
\hline Proyecto y dirección de las obras: & Amparo Berlinches Acín, arquitecta. \\
Colaboradores: & Enrique Nuere Mataúco, arquitecto, en los techos de madera. \\
& $\begin{array}{l}\text { Santiago Hernán Martín, arquitecto técnico. } \\
\text { Santiago Ferrete y Juan Ruíz, restauradores, en las pinturas murales. } \\
\text { Concepción Abad, arqueóloga, en la investigación histórica. }\end{array}$ \\
Empresas constructoras: & $\begin{array}{l}1^{2} \text { fase: Construcciones López Maurenza, S.L. } \\
2^{a} \text { fase: PECSA. }\end{array}$ \\
& $3^{\mathrm{a}}$ fase: Construcciones Barrionuevo. \\
Inversión total: & $\mathbf{5 5 . 5 0 0 . 0 0 0}$ ptas. \\
Fechas de realización: & $1986-1991$. \\
\hline
\end{tabular}

Iglesia de San Pedro, en Torremocha del Jarama

Torremocha se sitúa en el valle alto del Jarama en las estribaciones de la Sierra Norte madrileña en la proximidad del Conjunto Histórico de Torrelaguna, dominio de los Mendoza, a una distancia de Madrid de 63 km, y con una población de 227 habitantes.

\section{Reseña histórica y tipológica}

La Iglesia Parroquial de Torremocha, al igual que su homónima de Camarma, responde a la tipología rural característica. Así, sobre una pequeña torre vigía, quizás una atalaya de origen altomedieval, se adosa una pequeña ermita románica entre los siglos XIII y XIV, de una sola nave de mampostería cubierta con bóvedas de medio cañón y cabecera en ábside semicircular.

Hacia el siglo XV se prolonga la nave hacia los pies y se cubre mediante una armadura de madera atirantada. Es en 1556, al adquirir el estatus de parroquia dependiente de la Magistral de Alcalá de Henares, cuando se produce una nueva ampliación.
Por su costado oeste se adosa una nueva nave, dejando la ermita inicial como presbiterio, y por su lado este y por sus pies se erige un atrio porticado.

Nuevas obras más o menos importantes se suceden a lo largo de los siglos XVII y XVIII, pero no es hasta el siglo XIX, con la pretensión de dar mayor amplitud interior al templo, cuando se operan sobre el edificio las transformaciones más significativas. En 1865 se derriban los muros de carga que flanquean la nave principal y se sustituyen por arcos que descansan sobre pilastras; así, se incorpora el atrio al interior del templo y se tapian sus arquerías exteriores dejando únicamente unos pequeños óculos para la iluminación interior. La nave central se cubre con bóveda rebajada de rasilla y arcos fajones de escayola a imitación del ábside, quedando oculta de esta forma la armadura de madera. Se cierra el ábside con un retablo y se convierte en sacristía, dándole de yeso al interior. Hacia 1950 una nueva intervención añade un minúsculo y desafortunado cuerpo a la torre. 


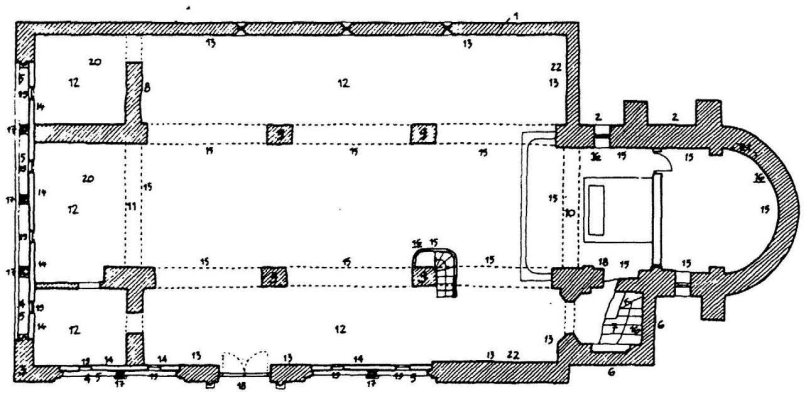

San Pedro. Torremocha. Planta antes de la restauración.

En febrero de 1986 y por iniciativa de la parroquia se inician unas pequeñas obras de reparación y de acabados interiores en la sacristía. Al proceder al picado de los yesos aparecen importantes fisuras en arcos y paramentos y restos de pinturas murales en el ábside, pinturas que parecen de cierta antigüedad. Todo ello hace que las autoridades municipales notifiquen a la Consejería de Cultura el estado de la iglesia y el hallazgo de las pinturas, y así el Centro Regional de Conservación y Restauración del Patrimonio se hace cargo de la investigación histórica del edificio y de la fijación de los criterios para su recuperación, en tanto se pueden presupuestar los fondos necesarios para la restauración integral del templo.

\section{La restauración}

La restauración se inicia en 1988, tras una limpieza y consolidación previa de las pinturas -se inicia el proceso de investigación histórica y arqueológica-, y se centra en la consolidación estructural del edificio, de sus muros, arcos, pilastras y cubiertas, con la recuperación y puesta en valor de las diferentes etapas de su historia, de forma que se consiga su lectura espacial y el proceso de su configuración arquitectónica y la de sus elementos esenciales; la

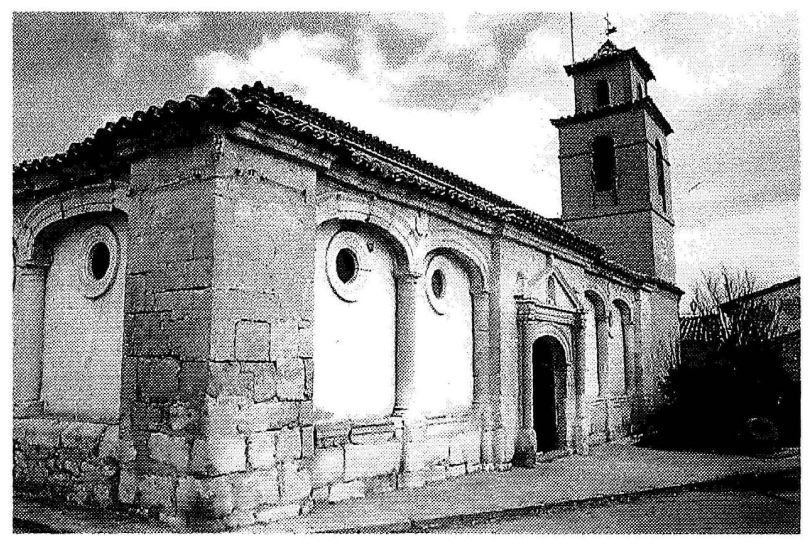

El atrio antes de la restauración.

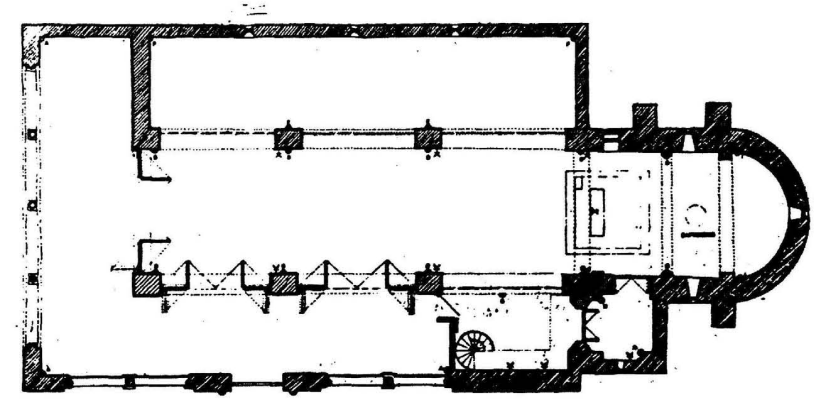

San Pedro. Torremocha. Planta actual.

apertura de las galerías y arcadas propiciando la recuperación del atrio como elemento esencial, la puesta en valor de la armadura de madera en la parte central, la restauración de la torre eliminando el último añadido, dando la posibilidad de una utilización plena y actual del templo.

Las actuaciones pueden resumirse en los siguientes apartados:

-Ábside: Recuperación interior de las pinturas murales, mediante una cuidadosa restauración de las mismas y de los huecos originales documentados, eliminación de humedades mediante la realización de un drenaje perimetral y restauración exterior de los revocos, ante la imposibilidad de recuperar el aspecto original por su estado, muy deteriorado y a su necesidad de protección.

-Nave central: Recuperación de la estructura original de madera eliminando la bóveda tabicada que la cubría. Los muros interiores, al pie del templo, construidos en tapial y mampuesto se encontraban muy mal conservados y próximos a la ruina, por lo que hubo que sustituirlos por otros en fábrica de ladrillo macizo. También se han reforzado o sustituido alguna de las pilastras sustentantes de la arquería interior.

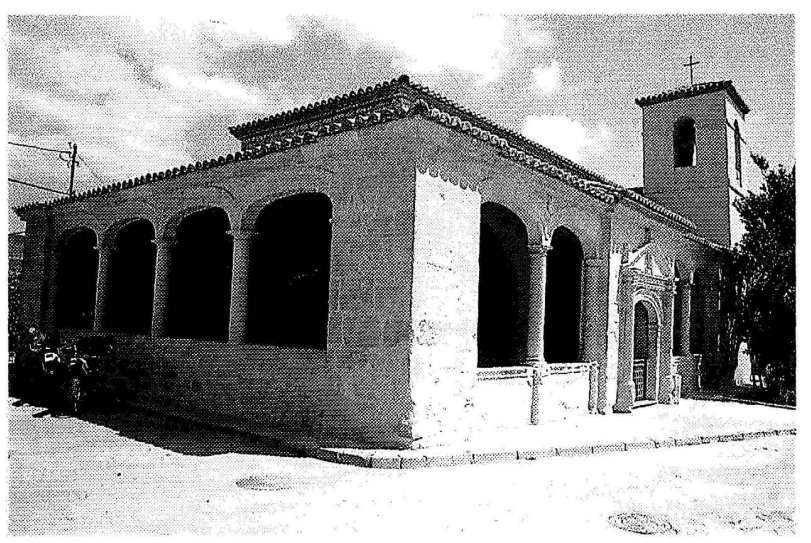

El atrio después de la restauración. 


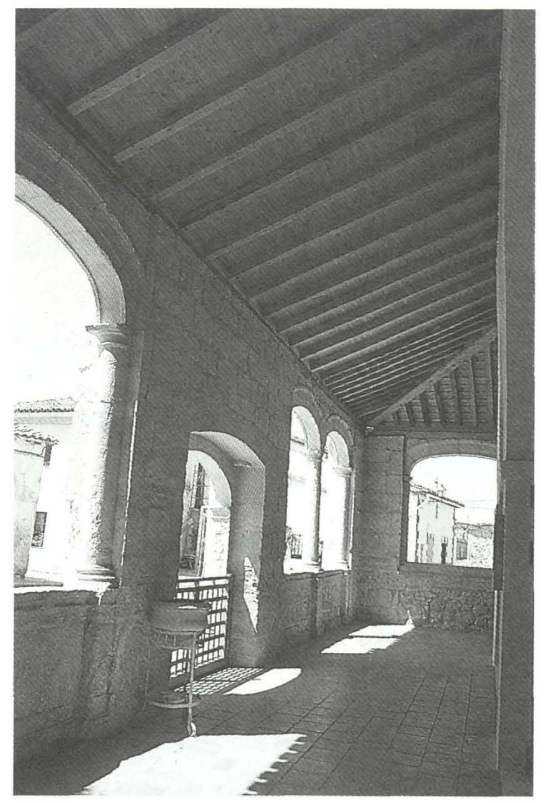

San Pedro. Torremocha. Interior del atrio restaurado.

-Cubiertas: Se desmonta para la construcción, en la coronación de los muros de un pie de ladrillo macizo sobre las arquerías, de un zuncho de hormigón armado. Se coloca el entramado de madera de pares y tablazón, y sobre una capa de hormigón aligerado, en sustitución de la torta de barro, la cobertura de teja curva con una máxima reutilización de elementos originales, tanto cerámicos como de madera.

-Arquerías del atrio: Se han desmontado los elementos de cornisa, enjutas, dovelas de los arcos y columnas en mal estado, procediéndose a su reparación o sustitución en su caso. Se han eliminado los cerramientos exteriores con los óculos para recuperar la apertura del atrio al exterior. La imagen

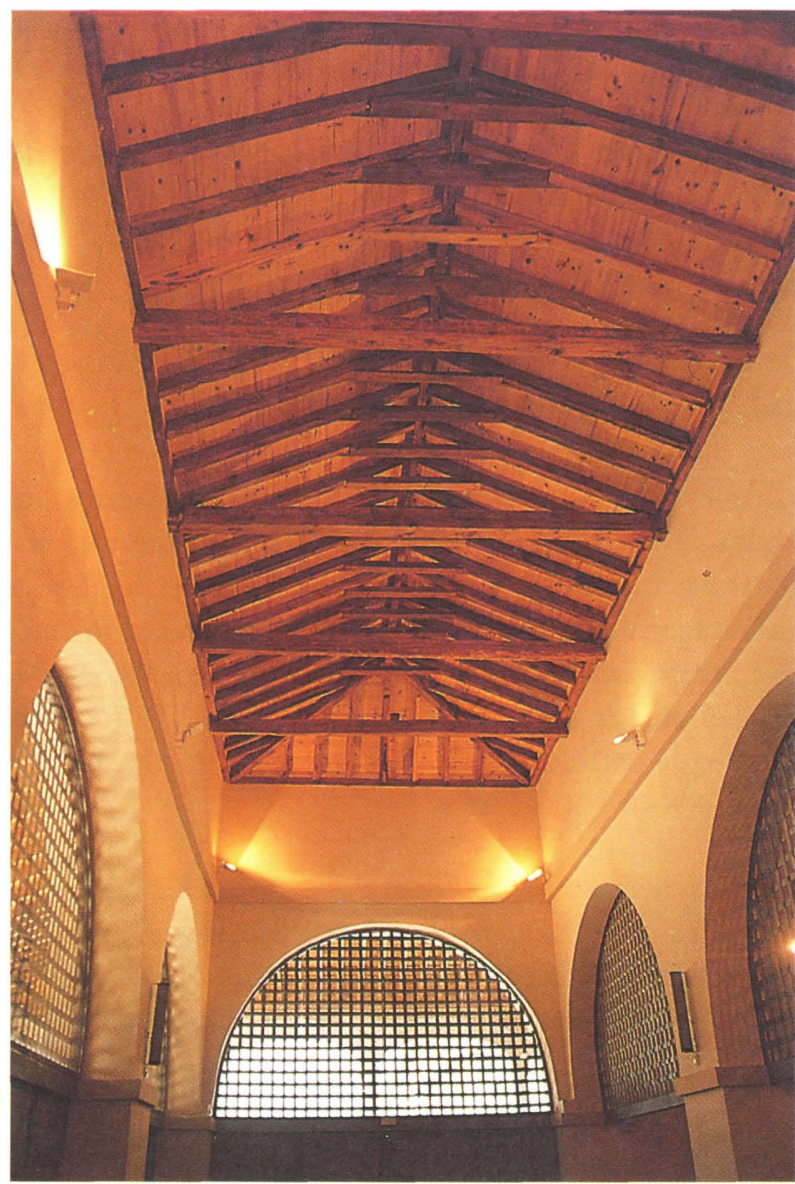

San Pedro. Torremocha. Interior de la nave.

interior del templo original de dos naves se recupera mediante el cierre de los arcos interiores, con elementos de celosía de pletina entrelazada, fijos en su parte superior y de apertura total en la inferior, lo que permite incorporar el atrio al templo en caso de ser necesario.

-Torre: Se rehace interiormente reconstruyendo el forjadillo interior y la escalera de acceso, e incorporando sobre él un nuevo elemento de coro lateral con estructura metálica claramente diferenciada de los elementos arquitectónicos originales. Al exterior se elimina el cuerpo añadido en los años 50, recomponiéndose su cubierta y su imagen de "torremocha", y se restauran los revocos con un tratamiento similar a los del ábside.

Ficha técnica

\begin{tabular}{|ll|}
\hline Proyecto y dirección de las obras: & $\begin{array}{l}\text { Rafael Lleonart, Javier Sardina y Felipe J. Pérez-Somarriba, arquitectos. } \\
\text { Fernando Ruíz Hervás, arquitecto técnico. }\end{array}$ \\
Empresa constructora: & Teodoro Santamaría, S.L. \\
Inversión total: & $\mathbf{5 9 . 0 0 0 . 0 0 0 ~ p t a s . ~}$ \\
Fechas de realización: & $1988-1992$. \\
\hline
\end{tabular}


Iglesia parroquial de San Vicente Mártir, en Braojos

Braojos es un pequeño núcleo de población serrano sobre la vía de unión de las dos mesetas de Castilla, en Somosierra. Tiene una población de 130 habitantes y dista $81 \mathrm{~km}$ de la capital.

\section{Reseña bistórica y tipológica}

La iglesia de San Vicente Mártir se edifica entre los siglos XV y XVIII, posiblemente sobre una atalayatorreón tardomedieval. La torre tiene la clásica decoración de bola y su escalera de caracol arranca del muro a media altura. En su parte baja, la capilla bautismal presenta bóveda de crucería. El resto de la iglesia es barroco con planta de cruz latina y cúpula sobre el crucero.

Junto a la nave central corre una segunda nave más estrecha, separada de la anterior por tres arcadas de medio punto sobre pilastras y columnas toscanas, adosándose a esta otra crujía, que pudo haber sido

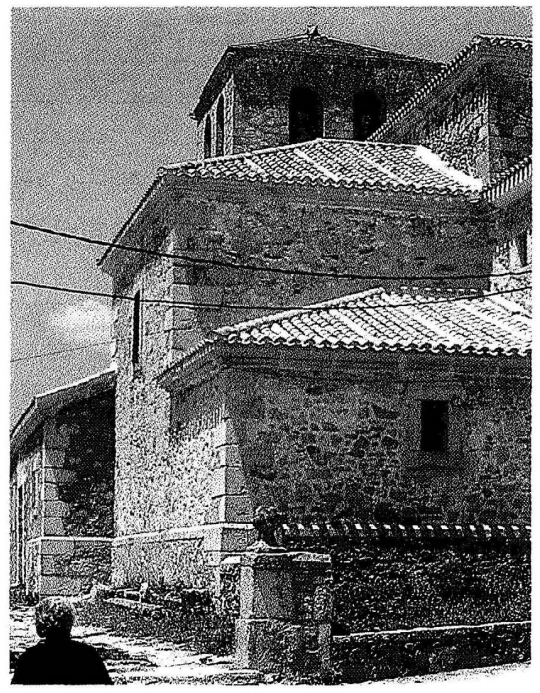

San Vicente. Braojos.

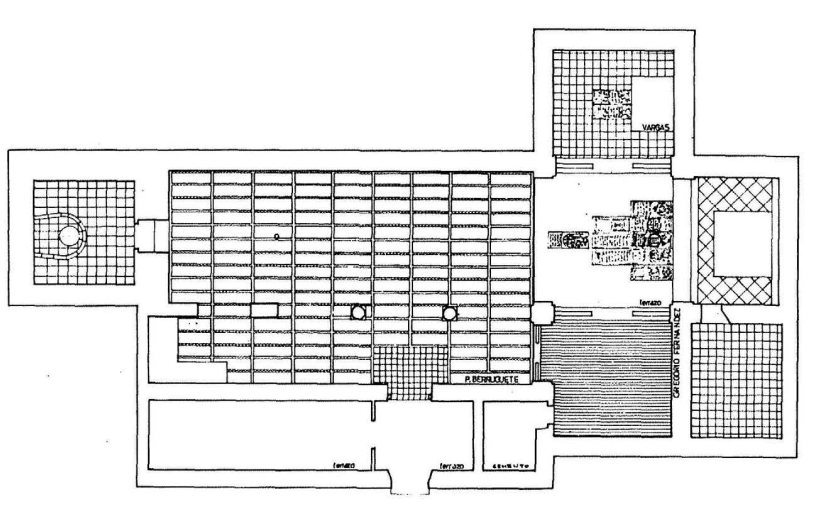

San Vicente. Braojos. Planta de suelos. inicialmente un atrio abierto a mediodía. La sacristía se une a un brazo del crucero y al presbiterio.

La iglesia posee en su interior unos excepcionales retablos, entre los que destacan el de San Miguel -en la capilla de los Vargas-, obra de Gregorio Fernández y Vicente Carducho, hacia 1628-1633; otro del taller de Carreño, hacia 1670, además de unas tablas del siglo XV incluidas en el retablo del lado de la épístola. Este conjunto de retablos fue dado a conocer por el historiador Pedro Navascués y ha sido estudiado por Alfonso E. Pérez Sánchez.

En el exterior del templo, de fábricas de mampuesto muy simples, rejuntadas con cal y recortadas a punta llana, destaca la volumetría de la torre que sirvió de base para su implantación.

La nave se cubrió, en origen, por una armadura de tipología mudéjar de la que únicamente quedaban, antes de iniciarse las obras, los tirantes.

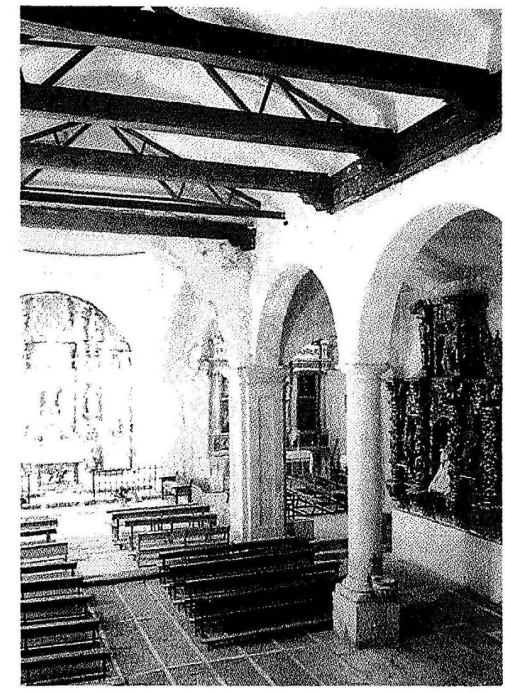

Interior antes de la restauración.

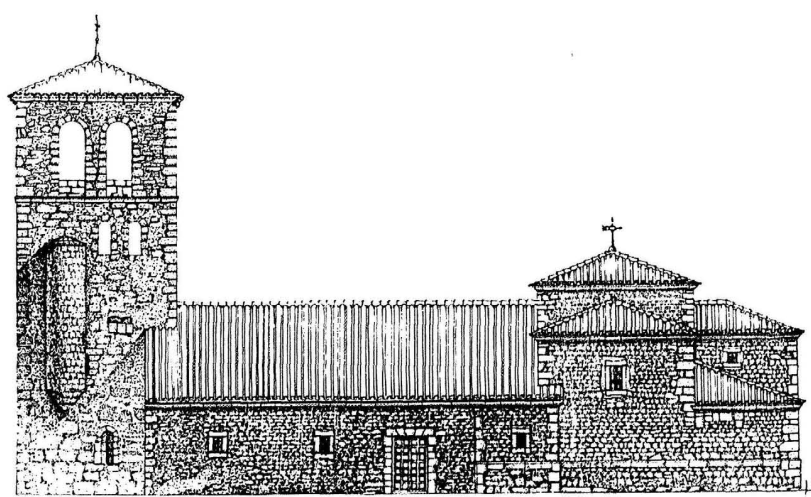

San Vicente. Braojos. Alzado principal. 
La iglesia es Monumento Histórico-artístico (expediente incoado en 1981).

\section{La restauración}

La armadura que conformaba la cubierta de la nave principal fue sustituida en época no muy lejana -algunos habitantes del lugar aún la recuerdan- por cinco dobles cerchas metálicas vistas que producían al interior un lamentable aspecto.

Por otro lado, en 1976, por el Obispado se llevaron a cabo unas obras de retejado con una inadecuada teja de cemento oscura que en poco resolvió las humedades que se manifiestan al interior del templo.

En una primera fase se intervino sobre los retablos, ya que era urgente la restauración de los mismos al haber estado sometidos a la acción del agua, y algunos de ellos presentaban problemas de estabilidad estructural y ataques de xilófagos.

En la segunda fase se devolvió a la iglesia su imagen original de una forma virtual. El planteamiento restaurador fue el de crear una estructura de artesa con formas de par y nudillo, recreando visual y estructuralmente la armadura mudéjar preexistente como atestiguaban los restos de sus tirantes, durmientes y estribos. Así, la nueva armadura de madera se diseña para apear el forjado existente y facilitar la eliminación de las cerchas metálicas que distorsionaban el espacio de la nave.

El mayor problema planteado en la realización de las obras fue la sustitución de la estructura de cubierta sin afectar a los retablos ya restaurados.

La estructura se organiza mediante un sistema de pares e hilera, tomando como referencia axial las

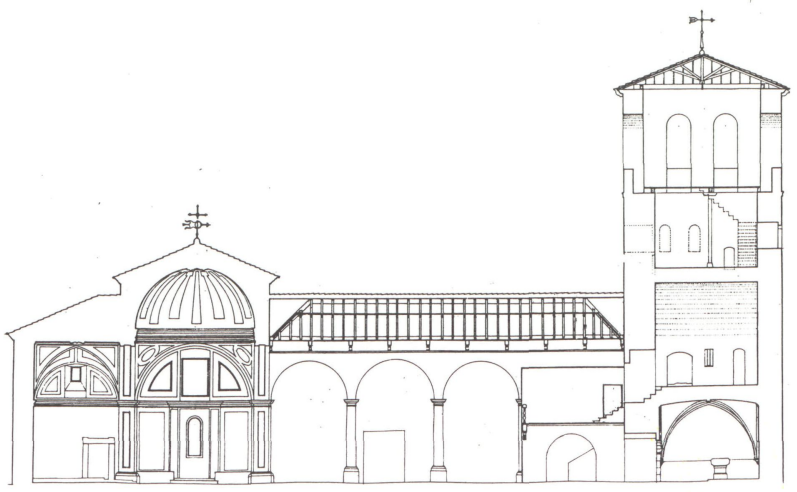

Sección longitudinal cerchas. Este sistema tiene un apoyo independiente de las soleras o durmientes existentes, entre otros motivos por no coincidir en el plano y por seguridad. Estos pares reciben equilibradamente la carga del plano actual de cubierta evitando su demolición y el dejar la iglesia descubierta y todo lo que contiene. Una vez colocados los pares y arriostrados por las hileras, y debidamente retacados y ajustados al techo, se procede a la eliminación de las cerchas metálicas.

Previamente se atirantó la estructura con tensores metálicos ajustables, atando la solera de apoyo de los pares, y pasándolos de forma no visible sobre los tirantes existentes, para ello se realizan zunchos armados de hormigón en la cabeza de los muros donde se anudan dichos tirantes. Estas operaciones se realizan con la cubierta descargada. La desigualdad de las pendientes lleva pareja la realización de recalces o suplementos de los pares en la pendiente mediodía. El acabado interior se realiza mediante tableros DM tratados para pintar, colocados sobre los pares en sustitución del ripiado.

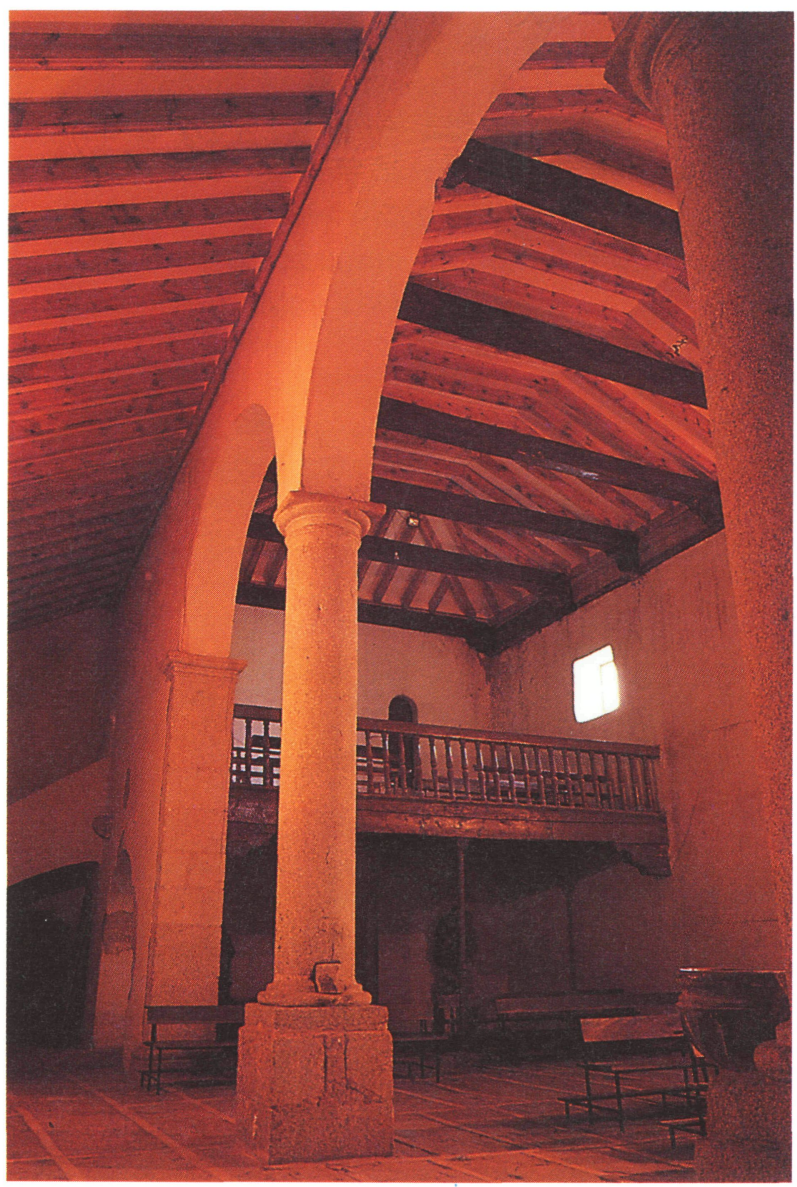

San Vicente. Braojos. Interior después de la restauración. 
En el techo de la nave lateral, liso y siguiendo la pendiente de la cubierta, se sobreponen los pares apoyados sobre soleras siguiendo la disposición de los de la nave central.

La nueva cobertura se realiza siguiendo la vieja técnica islámica de crear una torta de asiento de mezcla de barro y cal grasa sobre el forjado existente una vez impermeabilizado. Sobre la torta se coloca teja cerámica vieja, característica de la zona.

Durante las obras se acometieron las correspondientes peritaciones arqueológicas en la zona de la torre que han servido para la documentación del proyecto de restauración de la tercera fase, ya en ejecución.

\section{Ficha técnica}

\begin{tabular}{|c|c|}
\hline Proyecto y dirección de las obras: & $\begin{array}{l}\text { Ignacio Gárate Rojas, arquitecto. } \\
\text { Francisco Varela, arquitecto técnico. } \\
\text { Guadalupe Mendoza, restauración de los retablos. }\end{array}$ \\
\hline Empresas constructoras: & $\begin{array}{l}1^{\mathrm{a}} \text { fase, retablos: KYPSA. } \\
2^{\mathrm{a}} \text { fase, obras de restauración: Construcciones López Maurenza, S.L. }\end{array}$ \\
\hline Inversión total: & $\begin{array}{l}1^{\mathrm{a}} \text { fase, retablos: } \mathbf{1 3 . 5 0 0 . 0 0 0} \text { ptas. } \\
2^{\mathrm{a}} \text { fase, obras de restauración: } 18.000 .000 \text { ptas. }\end{array}$ \\
\hline Fechas de realización: & $\begin{array}{l}1^{\text {a }} \text { fase, } 1987-1989 \\
2^{\mathrm{a}} \text { fase, } 1989-1991\end{array}$ \\
\hline
\end{tabular}

Iglesia parroquial de la Concepción, en Chapineria

Chapinería es un municipio de la comarca de La Sagra, en zona de transición entre la sierra de Guadarrama y el valle del Tajo y en el área de influencia del Monasterio de San Lorenzo de El Escorial. Su población alcanza los 800 habitantes, si bien tal cifra se supera ampliamente los fines de semana y en verano. Se halla a una distancia de 50 $\mathrm{km}$ al suroeste de Madrid.

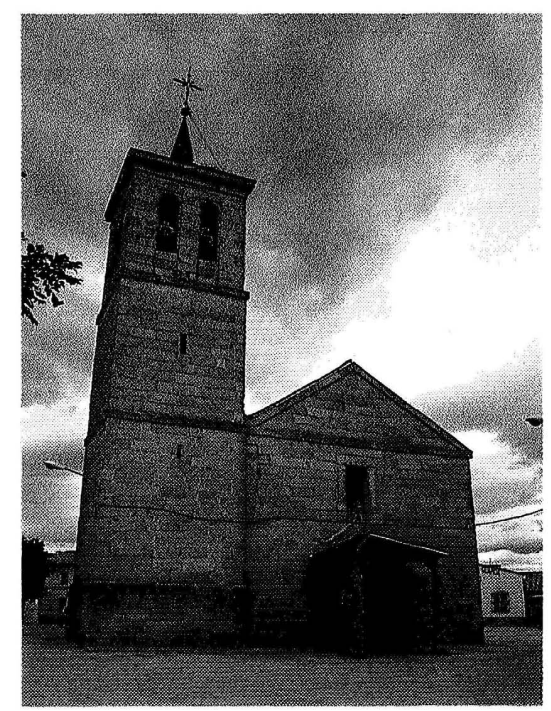

Iglesia de la concepción. Chapinería. Fachada principal.

\section{Reseña histórica y tipológica}

La Iglesia Parroquial de Chapinería es una fábrica de sillería de gran calidad curiosamente ejecutada de una vez, sin añadidos de relevancia de otras épocas, por artífices de El Escorial en el siglo XVI. La nave, de proporciones muy bajas, estuvo cubierta en origen con una artesa desarrollada a partir de

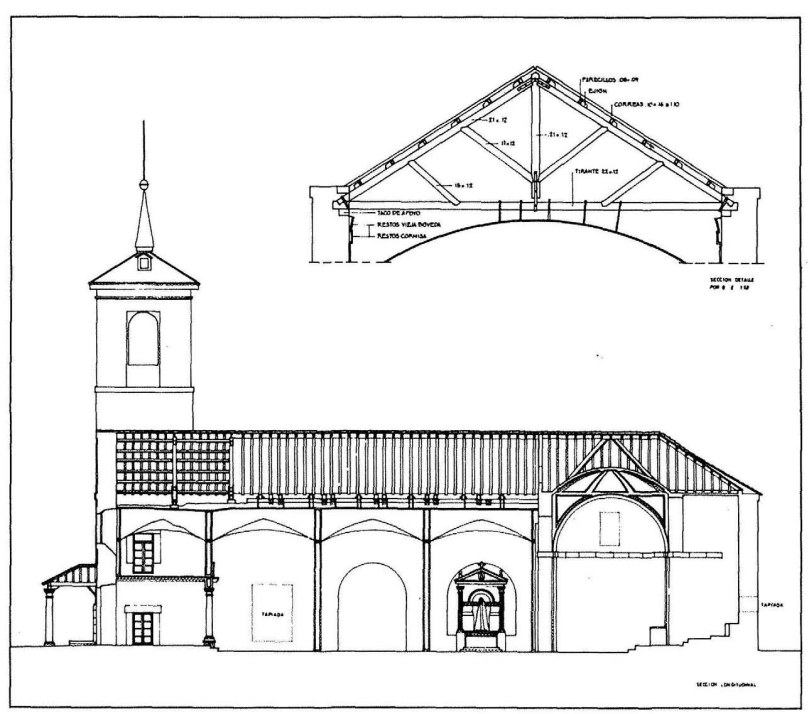

Sección longitudinal de la restauración y detalle de la estructura de la cubierta antigua. 
una estructura de madera de par y nudillo con tirantes.

Probablemente ya en el siglo XVII se añadiría una cabecera con crucero de escaso desarrollo, de ábside plano y cúpula baída. Todo ello en relación con el vecino palacio de La Sagra de construcción contemporánea.

Hacia el siglo XVIII se trazó, apoyándose en los tirantes, una bóveda encamonada de yeso de perfil plano redondeado en los apoyos. Con posterioridad, una nueva intervención traza una nueva bóveda de perfil más cóncavo, siempre a partir de la cota de los tirantes como punto más alto.

Por último en los años 50, tras una intervención a fondo en la estructura del tejado que sustituyó gran parte de la solución de par y nudillo con tirante, en ese momento ya muy renovada con criterios nada ortodoxos y en cualquier caso sobre la base que permanecía oculta, por cerchas de madera a la "española". Bajo todo ello se colocó una nueva sucesión de bóvedas de arista de escayola que disminuyó y acható más aún el volumen interior, desfigurando el esquema estructural y las proporciones originales.

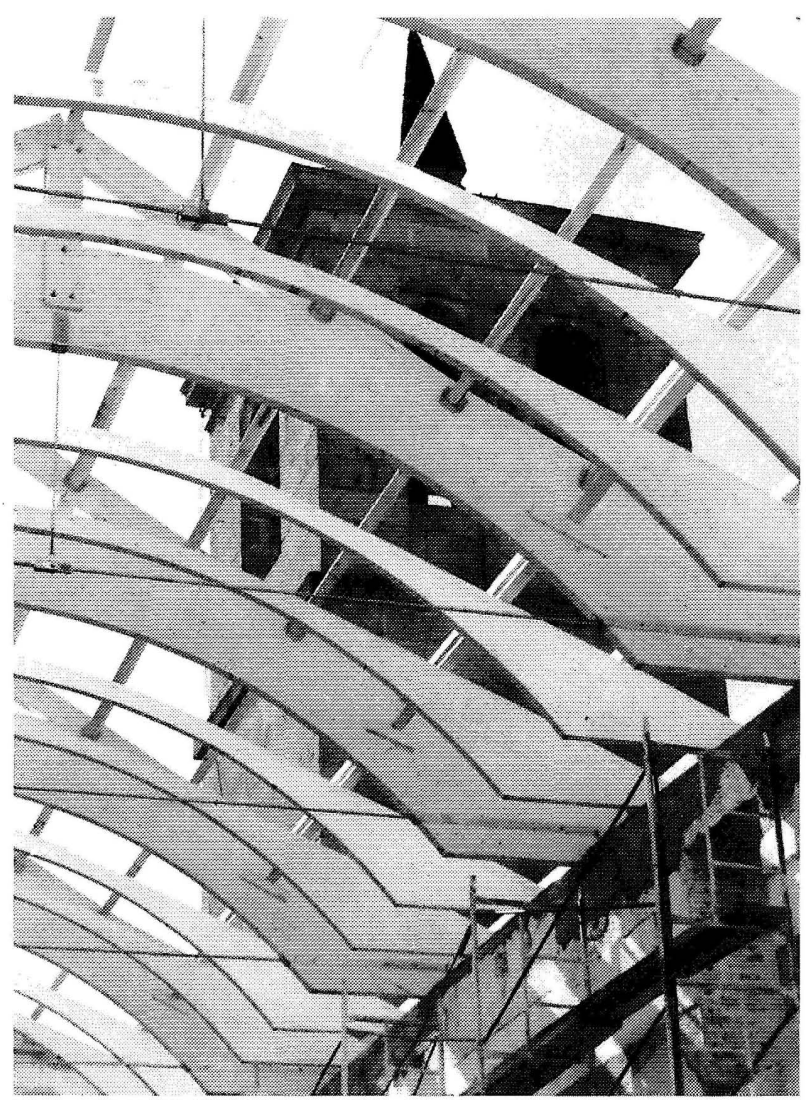

Iglesia de la Concepción. Chapinería. Nueva estructura de la cubierta.

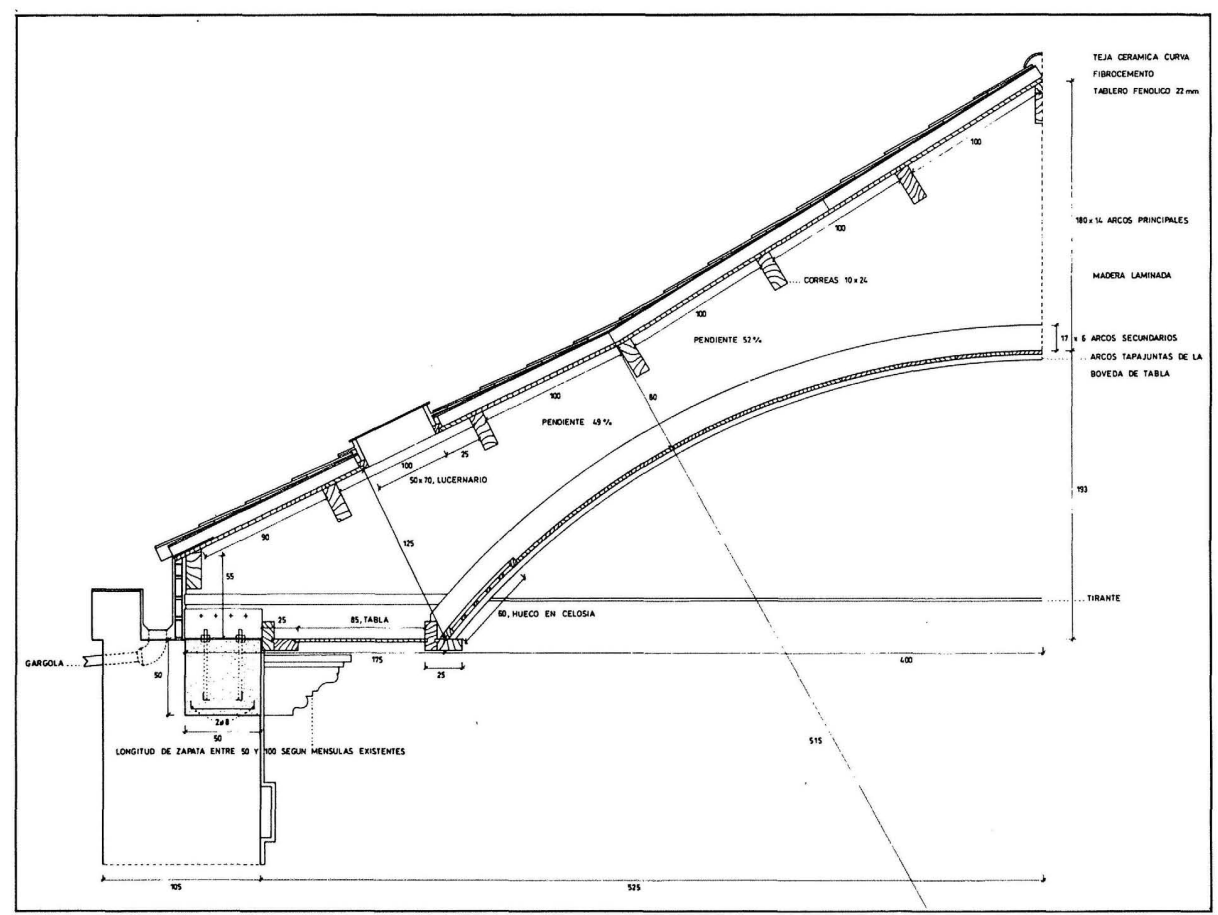

Iglesia de la Concepción. Chapineria. Detalle de la sección transversal. 


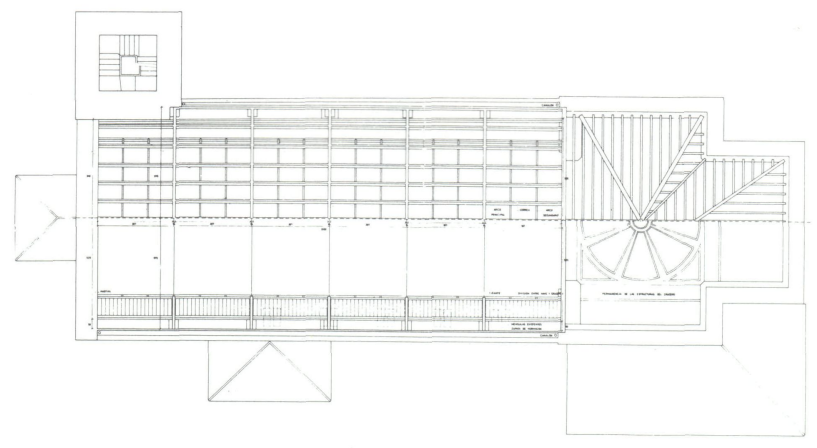

Planta y estructura de cubierta.
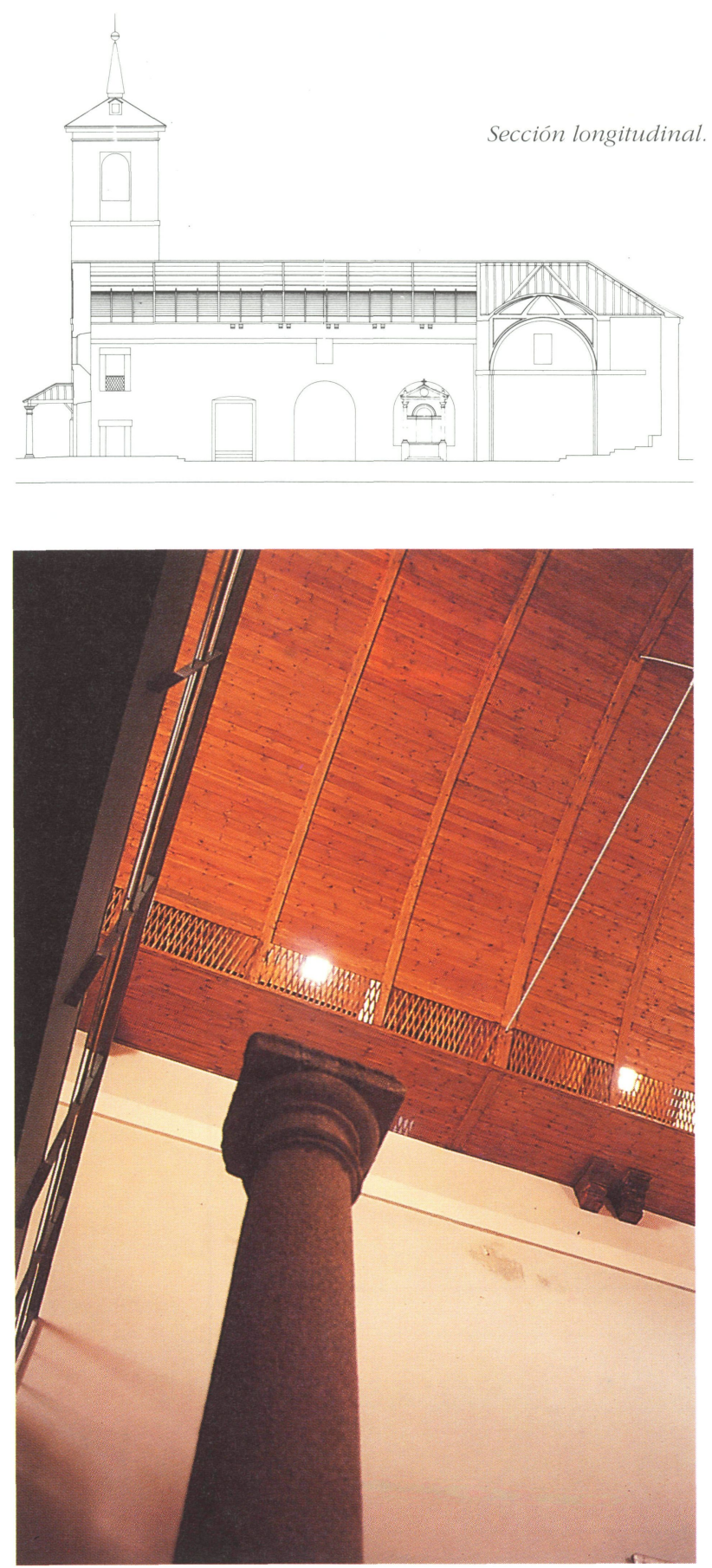

Detalle del nuevo coro.

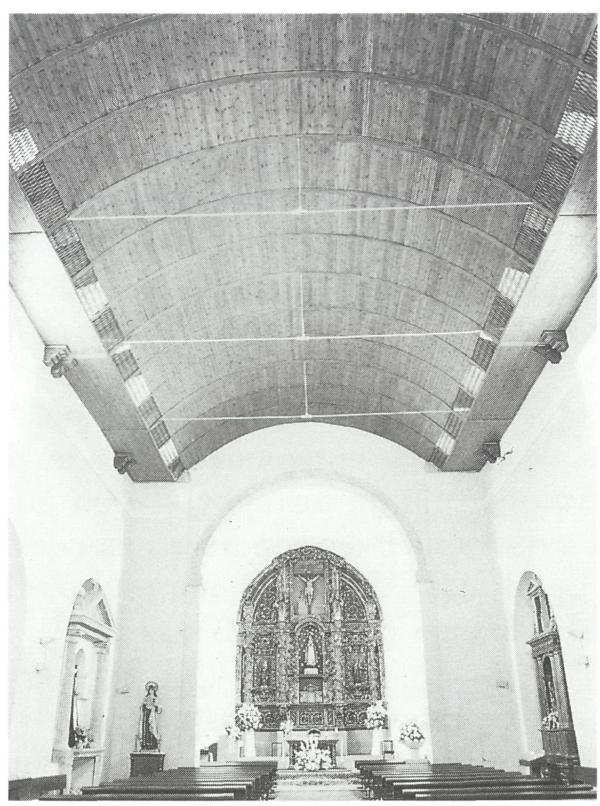

Iglesia de la Concepción. Chapinería. Interior restaurado.

También fue construido un coro, a los pies, aprovechándose para ello unas columnas toscanas de granito procedentes de otro lugar, todo ello con muy poco acierto. Se realizan también unos pequeños atrios sobre las puertas de acceso en el exterior.

\section{La restauración}

Cuando las bóvedas comenzaron a arruinarse, presionadas por la rotura de las cerchas de la última reforma, se decide acometer la restauración mediante una solución que, recuperando el volumen inicial, retomara con lenguaje actual la concavidad de la artesa que lo conformó, respetando en posición las ménsulas de sus tirantes, único resto conservado, volviendo a la solución primitiva de tratamiento unitario de bóveda y cubierta, es decir la esencia de la artesa. Así, se proyecta una cobertura que resuelve con modos actuales -constructivos y figurativos- los problemas planteados.

De esta manera, la nueva cobertura del espacio se plantea con una estructura unitaria bóveda-cubierta, compuesta por formas de madera laminada-encolada de unos diez metros de luz, con tirantes metálicos que trabajan a tracción, eliminando los empujes horizontales sobre las paredes.

Dichas formas tienen un perfil de arco por la parte inferior y a dos aguas por la superior, ajustándose a la forma actual de cubierta. El trasdós de las formas soporta las hileras del tejado y su intradós sirve de directriz a la bóveda de cañón de tablas de madera 
que aparece al interior, y en sus laterales deja pasar la luz a través de una estrecha celosía también de madera que se corresponde con unas claraboyas practicadas en la cubierta, que se repone con la teja original.

La disposición de esta nueva cubierta permite que se vean los restos de la primitiva, es decir la imposta y parte de los primitivos canes, permitiéndose así una lectura arqueológica del monumento.

Las paredes de la iglesia recuperan los huecos antes tapiados y sus paramentos mantienen sus características iniciales.

El coro se sustituyó respetando, en una referencia culta, las columnas que lo sostenían, pero liberadas de su función portante, haciendo notar su carácter espúreo.

También se han sustituido los pavimentos en su tota-

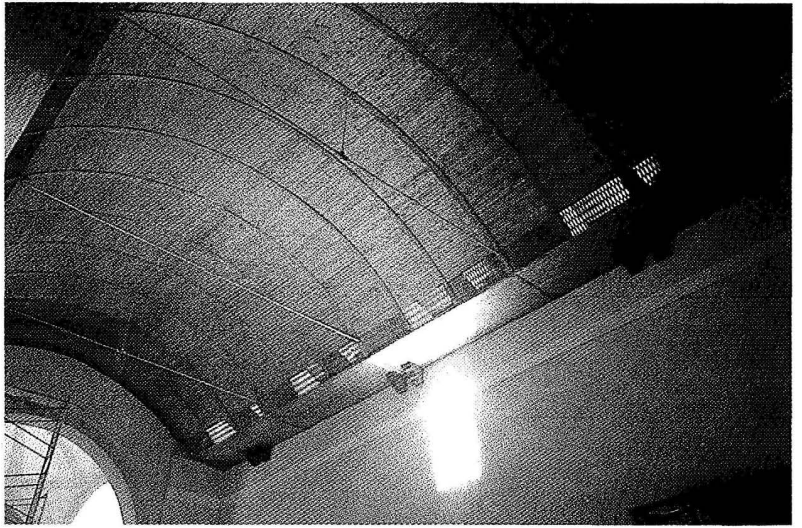

Iglesia de la Concepción. Chapinería. Detalle de la nueva cubierta.

lidad a excepción de los del altar mayor, por un terrazo en dos colores.

Unas pequeñas gárgolas en tubo de cinc se encargan de realizar la evacuación de las aguas en la cubierta.

\section{Ficha técnica}

\begin{tabular}{|ll|}
\hline Proyecto y dirección de las obras: & $\begin{array}{l}\text { José Ignacio Linazasoro, arquitecto. } \\
\text { Luis Sesé, arquitecto colaborador. } \\
\text { Santiago Hernán y Juan Carlos Corona, arquitectos técnicos. }\end{array}$ \\
Empresa constructora: & GEOCISA. \\
& Estructura de madera: Pierre Lespiaucq. \\
Inversión total: & $\mathbf{4 6 . 2 0 0 . 0 0 0 ~ p t a s . ~}$ \\
Fechas de realización: & $1989-1991$. \\
\hline
\end{tabular}

\section{publicación del ICCT/CSIC}

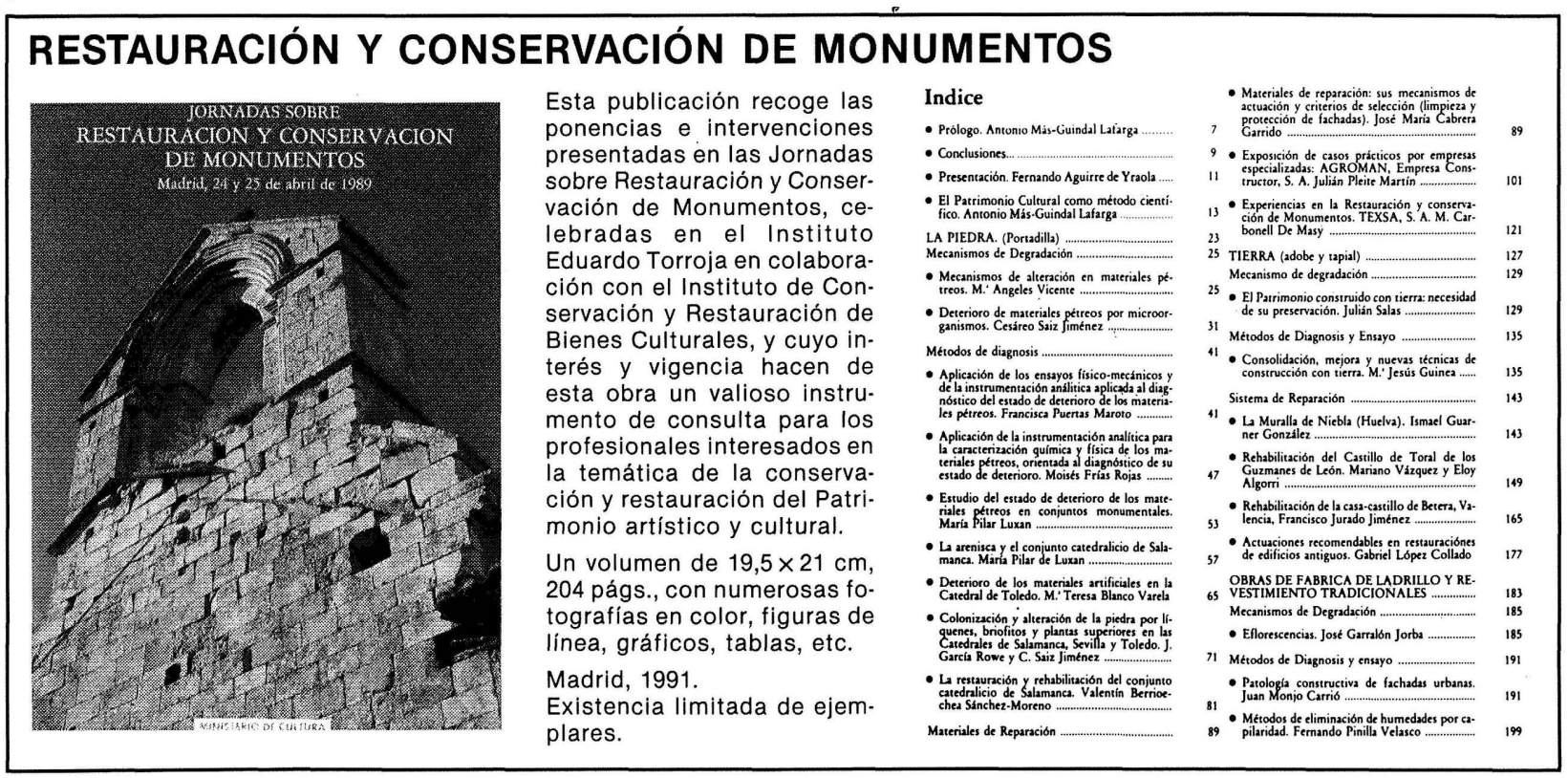

